\section{Comparison of a Rapid Readout Biological Indicator for Steam Sterilization With Four Conventional Biological Indicators and Five Chemical Indicators}

\section{To the Editor:}

In comparing the performance of the rapid readout biological indicator for steam sterilization with four conventional biological indicators and five chemical indicators, Dr. Rutala and colleagues conclude that its sensitivity "parallels" that of the others. ${ }^{1}$ It is to be noted that, to ensure uniform exposure conditions, all of the indicators were tested simultaneously (being placed horizontally, evenly, and without overlap throughout a single mesh-bottom surgical tray). For purposes of this test, this arrangement was most satisfactory.

However, the question that has to be answered is whether or not any of the devices truly reflect the operating efficiency of the sterilizer(s) in which they may be used.

For example, Dr. Rutala references the comprehensive evaluation of the rapid readout device that was done earlier. ${ }^{2}$ In that study, the device was wrapped in what was described as a "standard 16-towel pack recommended by AAMI" (Association for the Advancement of Medical Instrumentation) that weighs $3.3 \mathrm{lbs}^{3}$ The level of the challenge provided by that pack compared to that of the historic $12-1 \mathrm{~b} 12$ in $\times 12$-in $\times 20$-in configuration that in itself contained 12 towels is an issue of concern. ${ }^{4}$ The researchers associated with the initial study of the rapid readout indicator study have stated that "a denser and larger test pack could result in additional positive indicators at the times we tested, and we would hope that AAMI will continue to seek a standard pack that realistically simulates the actual inuse conditions of these sterilizers." 5 For whatever reason, that has not as yet been done.

In the interim, the state of affairs in in-hospital packaging practices is being influenced dramatically by two factors: (1) the conversion from a timerelated to event-related shelf-life and (2) the reprocessing of what heretofore have been single-use devices. To accommodate these trends, an entirely new generation of "barrier" quality packaging materials is being introduced. Because the operational specifications for the steam sterilizer are predicated on the use of readily permeable materials and the indicators do not even truly reflect the operating efficiency of the unit, who then can vouch for the sterility of the products being processed?

It has been said that "a sterilizer is nothing more than a piece of equipment that is designed to achieve a certain level of micro-lethality. What you need to know is, how was that determined?" 6 Under the circumstances, the same could be said about the devices being used to demonstrate its operating efficiency.

\section{REFERENCES}

1. Rutala WA, Jones SM, Weber DJ. Comparison of a rapid readout biological indicator for steam sterilization with four conventional biological indicators and five chemical indicators. Infect Control Hosp Epidemiol 1996;17:423-428.

2. Vesley D, Nellis MA, Allwood PB. Evaluation of a rapid readout biological indicator for $121^{\circ} \mathrm{C}$ gravity and $132^{\circ} \mathrm{C}$ vacuumassisted steam sterilization cycles. Infect Control Hosp Epidemiol 1995;16:281-286.

3. Association for the Advancement of Medical Instrumentation. Good Hospital Practice: Steam Sterilization and Sterility Assurance. Arlington, VA: ANSI/AAMI:ST46-1993.

4. Belkin NL. The new 16-towel test pack: is it a challenge to the sterilizer? Infect Control Hosp Epidemiol 1995;16:495-496.

5. Vesley D, Nellis MA, Allwood PB. Infect Control Hosp Epidemiol 1995;16:496. Letter.

6. 'Buyer beware' on sterilizer purchases. Hospital Purchasing News; March 15, 1996;20 (3):36.

Nathan L. Belkin, PhD Clearwater, Florida

\section{The authors reply}

We thank Dr. Belkin for raising the issue of whether the introduction of new packaging material will decrease the ability to achieve sterilization of materials contained in the packs. For steam sterilization to occur, the steam must penetrate to the material to be sterilized. We agree with Dr. Belkin that the ability of current and new sterilization procedures to penetrate the new packaging materials should be studied rigorously before these materials are introduced.

Our study compared the sensitivity of a rapid readout biological indicator for steam sterilization with chemi- cal indicators and conventional biological indicators. 1 Our data suggested that a 3-hour rapid readout biological indicator was equivalent to standard 48-hour biological indicators and that chemical indicators do not consistently perform as well as biological indicators in appropriately monitoring sterilization. We believe that the relative sensitivity of the biological indicators would not be affected by enclosing them in either conventional or new packaging material and would reflect the true state of sterilization.

\section{REFERENCE}

1. Rutala WA, Jones SM, Weber DJ. Comparison of a rapid readout biological indicator for steam sterilization with four conventional biological indicators and five chemical indicators. Infect Control Hosp Epidemiol 1996;17:423-428.

William A. Rutala, PhD, MPH David J. Weber, MD, MPH

University of North Carolina at Chapel Hill Chapel Hill, North Carolina

\section{Vancomycin Use in a University Medical Center: Comparison With Hospital Infection Control Practices Advisory Committee Guidelines}

\section{To the Editor:}

Evans and Kortas recently reported the use of vancomycin in a teaching hospital. ${ }^{1}$ In their study, only $35 \%$ of vancomycin orders written were consistent with Hospital Infection Control Practices Advisory Committee (HICPAC) guidelines. We hereby report on our experience on the use of vancomycin prior to and after HICPAC recommendations were available for preventing the spread of vancomycin-resistant organisms.

A retrospective survey of vancomycin use in 27 hospitalized patients during September 1994 showed that vancomycin use was appropriate in 16 (59\%) of 27. Appropriate use of vancomycin was defined as using vancomycin for (1) serious gram-positive infections in patients with serious $\beta$-lactam allergy; (2) surgical 